\title{
As- built inventory of the office building with the use of terrestrial laser scanning
}

\author{
Marek Przyborski ${ }^{1}$, Paweł Tysiąc ${ }^{1, *}$ \\ ${ }^{1}$ Gdansk University of Technology, Faculty of Civil and Environmental Engineering, Department of Geodesy, Narutowicza St. 11/12, \\ 80-233 Gdansk, Poland
}

\begin{abstract}
Terrestrial Laser Scanning (TLS) is an efficient tool for building inventories. Based on the redlaser beam technology it is possible to provide the high accuracy data with complete spatial information about a scanned object. In this article, authors present the solution of use a TLS in as-built inventory of the office building. Based on the provided data, it is possible to evaluate the correctness of built details of a building and provide information for further construction works, for example an area needed for Styrofoam installation. The biggest problem in this research is that an error which equals over $1 \mathrm{~cm}$ could generate costs, which could be a problem to cover by a constructor. Based on a complicated place of the construction works (centre of a city) it was a challenge to maintain the accuracy.
\end{abstract}

\section{Introduction}

In according to the polish and international literature it is needing to perform a proper inventory of buildings [1][2]. Geodetic measurements are present on every step of buildings construction stages from map to design proposes to as-built inventory. Crucial is to maintain a proper accuracy of the data in every of stage.

Nowadays, one of the option for fast and accurate data collecting is the use of laser scanning technology. Based on the red- beam laser technology could provide a spatial information about the object, which is represent by millions of points. The most challenging is to operate on such data which require lots of computing power by hardware. It could be a disadvantage, but it has to be mentioned that point cloud is not a final product. From point cloud, for example CAD drawings could be generate and to operate on such data is not a problem.

One of the advantage of use such a technology is that besides of the information about coordinates of points, the amplitude, reflectance values are registered. Reflectance of the surface could be defined as its effectiveness in reflecting a radiant energy from that surface. This application is reliable in estimate a condition of the materials [3][4] and ensure the view of the point cloud in so called 'false colours'. That gives the user opportunity to have a valuable information about object's surfaces.

Moreover, in describing laser scanning technology, we could distinguish three systems: terrestrial, mobile and airborne. Main differences between them are accuracy of the provided data and land they could covered in one measurement mission. For single construction, the best is to use the most accurateterrestrial laser scanning [5].

\section{Mission planning}

The object of interest is placed in Gdansk, Poland and is represented by a construction of a new office building. The approximate location with geographical coordinates is presented in Fig. 1 as the print screen from Google Earth software inside the red polygon.

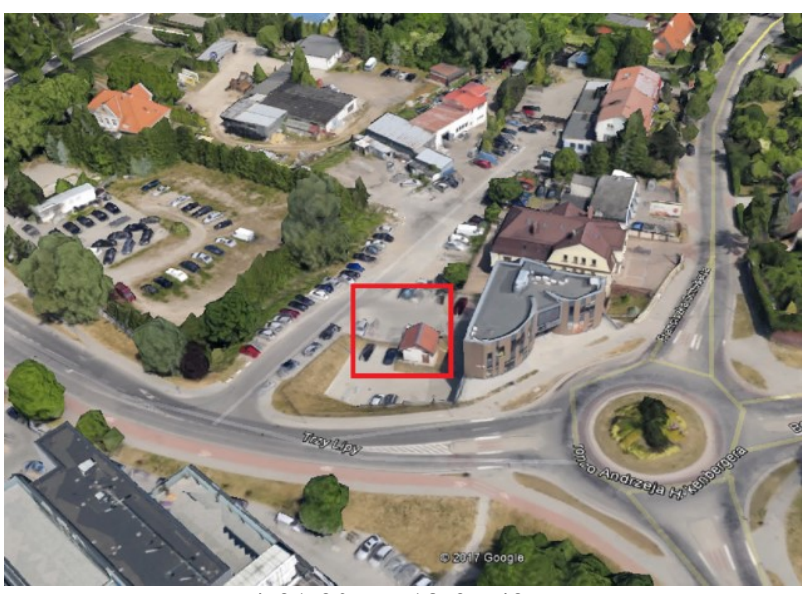

$$
54^{\circ} 21^{\prime} 20^{\prime \prime} \mathrm{N} 18^{\circ} 35^{\prime} 42^{\prime \prime} \mathrm{E}
$$

Fig. 1 The area of interest [source: Google Earth]

Assumptions of the whole measurement was to obtain the $1 \mathrm{~cm}$ accuracy for checking the correctness of zero state of a building for example, the size of carved out windows and doors holes. What is more, walls deviations were calculated and every of dimensions between windows and doors holes were estimated because of a Styrofoam, which was going to install. Based on the accuracy assumption, the constructor could reduce the cost of the materials. It has to be mentioned

\footnotetext{
* Corresponding author: pawtysia@pg.edu.pl
} 
that a lot of Styrofoam during the installation is going to the trash. With the use of laser scanning technology, it could reduce not only costs but also the time need for Styrofoam installation.

The laser scanner which has been used in this experiment was the Riegl VZ- 400, provided by Apeks company, placed in Gdansk, Poland. According to the producer brochure about the equipment, Riegl VZ-400 is able to collect the data with $3 \mathrm{~mm}$ precision and $5 \mathrm{~mm}$ accuracy [5]. The one more problem to investigate in post-processing the data is the level of noise, which has to be filtered before the data processing. Moreover, the Riegl ensure the user that the instrument could collect 122 thousand points per second in High Speed mode. Based on that instrument model and measurement specification, a one scan pattern for each wall is required and analyse separately.

Unfortunately, the situation was different from presumed. The whole object was enclosed by metal plates, preventing from enter into the construction site. Also, a close neighbourhood of road and other buildings was a problem for data acquisition. It was not possible to cover assumptions. It was a need to create a lot more scan stations. Authors placed 15 scan positions. The alignment of that positions and estimate the perfect, according to the project place of walls for deviations calculations was crucial. The Fig. 2 is presenting the scanned object.

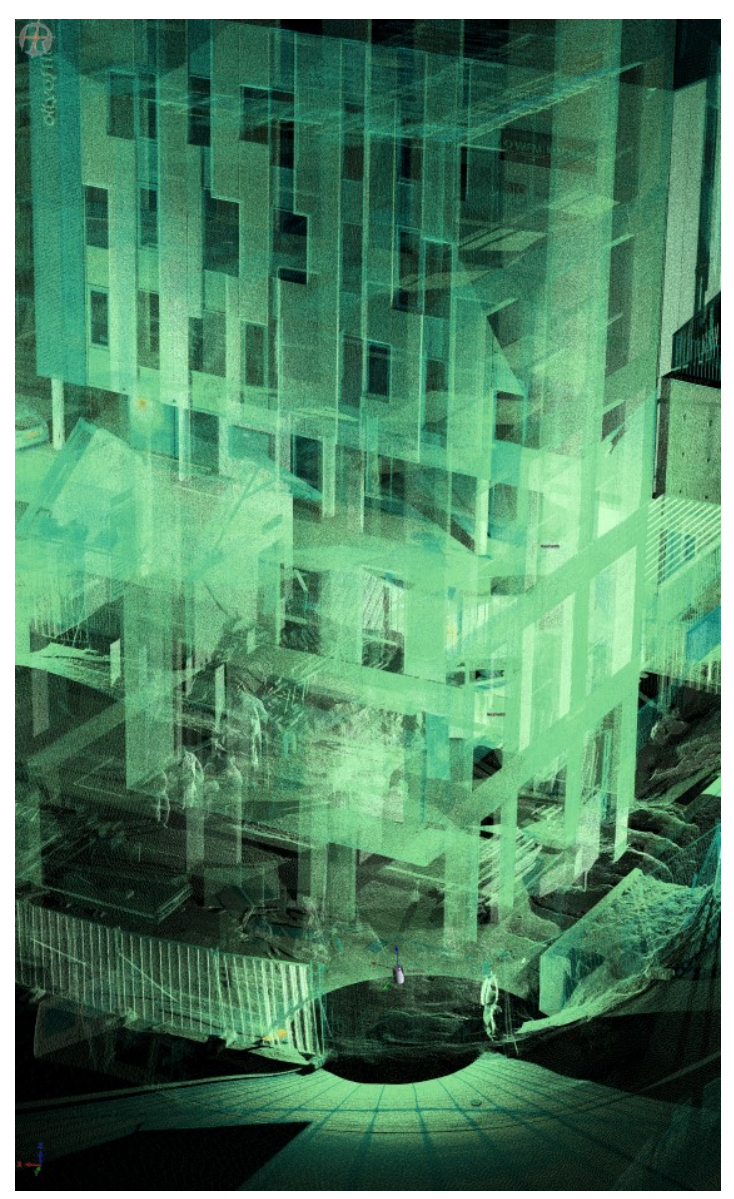

Fig. 2. The view of a scanned object.
The Fig. 3 is presenting the places where the instrument measured the object.

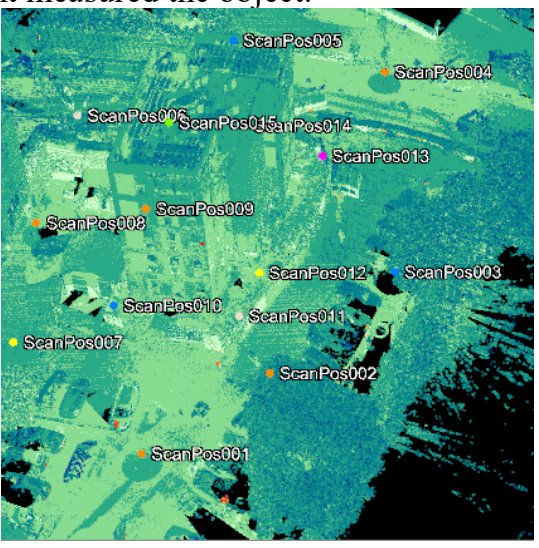

Fig. 3. Positions of the instrument.

\section{Alignment and plane estimation}

To align scan positions between each other, the Iterative Closest Points method was used. To maintain the accuracy of the data, first it had to indicate the scan positions belonging to one scanned wall. Alignment 15 scan positions could generate an error, much exceeding of the assumed. After the alignment, the value of noise has to be estimated. Whole gained data accuracy has not exceeded $1 \mathrm{~cm}$. The process of alignment evaluate is described below.

First, scan positions number 1, 2 and 7 was assigned to the North wall. Scan positions number 2, 3, 11, 12 and 13 was assigned to the West wall. Scan positions number 4, 5, 14, 15 was assigned to the South wall and 5, 8, 9, 10 to the East wall. The alignment results were presenting below in Fig. 4 for the North wall, Fig. 5 for the West wall, Fig. 6 for the South wall and Fig. 7 for the East wall. Every of standard deviations results for each wall are presenting in meters.

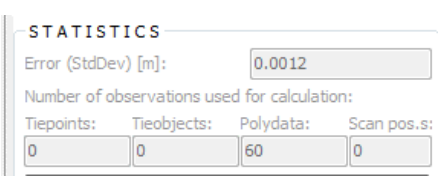

Fig. 4. The alignment results for the North wall.

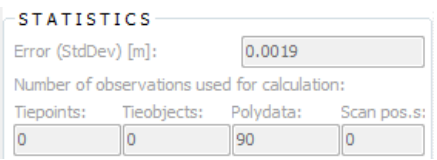

Fig. 5. The alignment for the West wall.

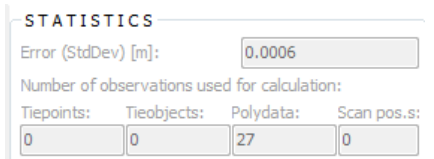

Fig. 6. The alignment for the South wall. 


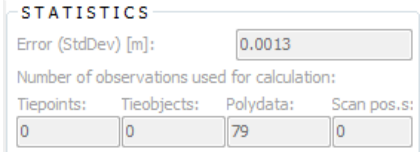

Fig. 7. The alignment for the East wall.

The plane was estimated with the use of the least square- method by indicate 8 points, belonging to the walls at the bottom of walls. The representation of chosen points is presenting in Fig. 8. The same workflow was performed for each wall. The reason for placing points was that from the level 0 to the height of 1 meter it could be observed the hypothetical, non - angular deviated walls of the building. From that wall (It could be named- reference), the angular, real deviation was estimated.

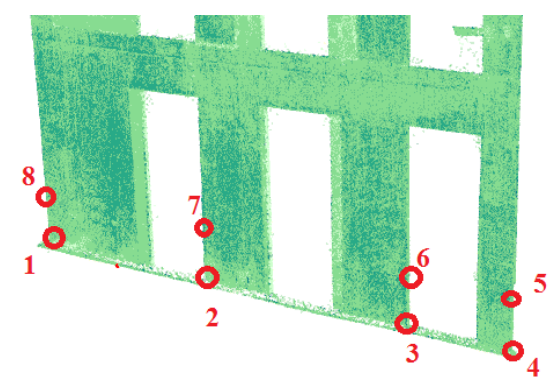

Fig. 8. Chosen points for plane matching which indicate the wall according to its perfect position.

\section{Experiment results}

First, dimensions of windows, doors gaps were measured and comparison between measured ones and from an architectural plan sizes was performed. The results on the example of North wall (down part of the wall, the same as its seen in Fig. 8) was presented in Fig. 9. It could be noticed that the differences between sizes are significant and up to $3.5 \mathrm{~cm}$ with the accuracy of $1 \mathrm{~cm}$.

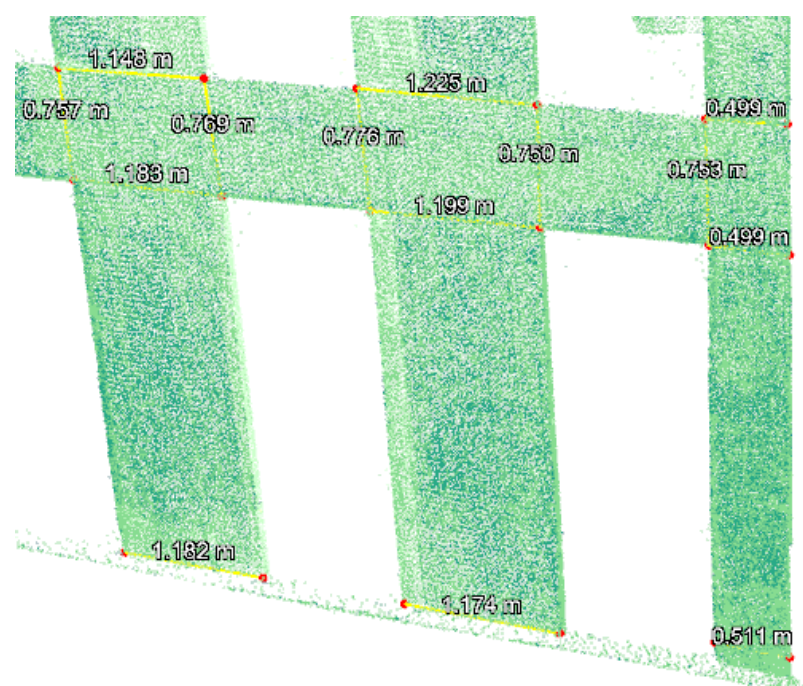

Fig. 9. Examples of windows gaps dimensions.

More challenging was estimate the angular deviations of walls from a reference. Besides, the measurement accuracy was up to $1 \mathrm{~cm}$, the plane matching error has to be estimated. It was computed as standard deviation values for points distances which was taken into consideration and belonging to that plane. With that process, the standard deviation value equals approximately $5 \mathrm{~mm}$. Angular deviations for each wall are presented in Fig. 10 for North, Fig. 11 for South, Fig. 12 for West and Fig. 13 for East. Values are presented in meters.

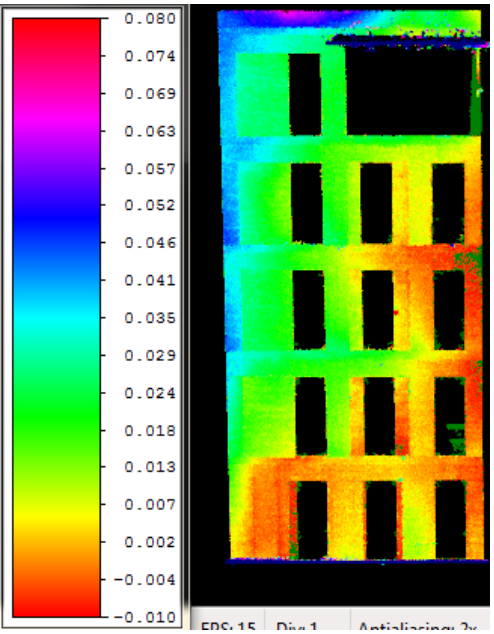

Fig. 10. Angular deviations for North wall in meters

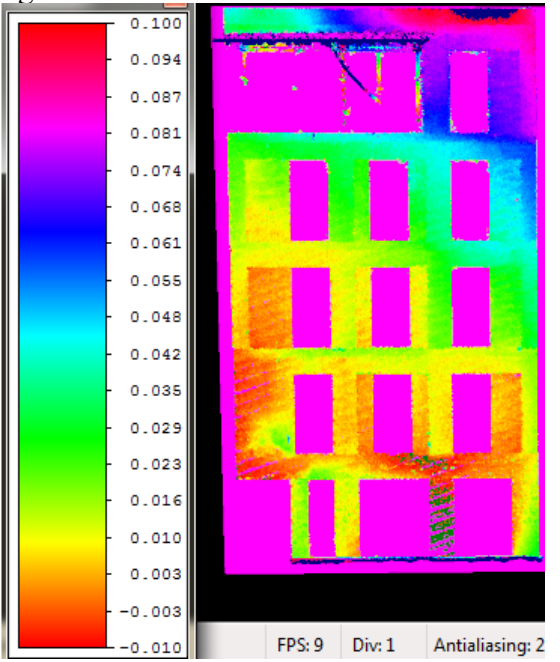

Fig. 11. Angular deviations for South wall in meters. 


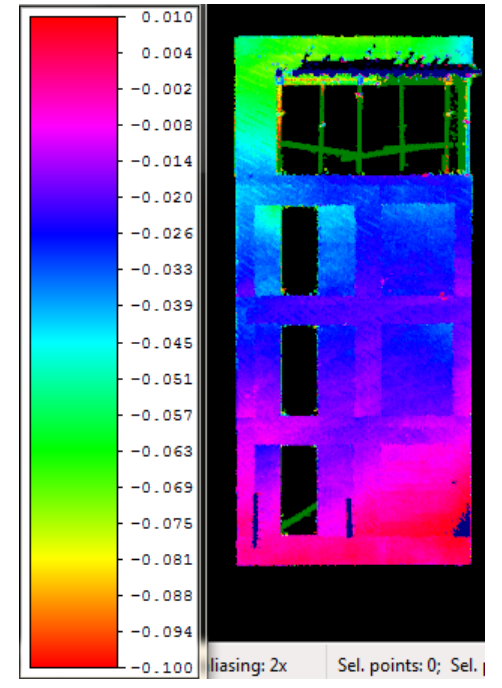

Fig. 12. Angular deviations for West wall in meters.

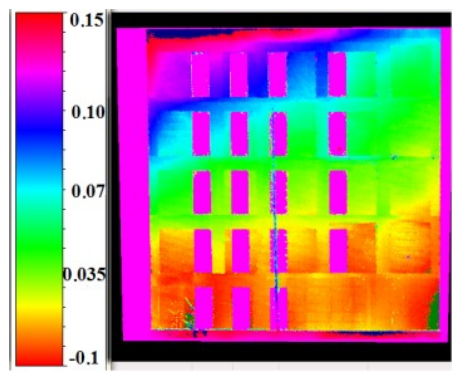

Fig. 13. Angular deviations for East wall in meters.

\section{Conclusions}

Terrestrial Laser Scanning is an effective tool for as-built inventory performance. It could be used not only in size of a construction estimation but also for digital model creation. Based on that model an angular deviation of the walls could be estimated with high precision and accuracy and based on that data, irregularity could be noticed. Most of the projects are difficult in processes of data acquisition and post- processing but the results could be fully operational. Besides, the laser scanning technology could provide the non- invasion measuring process from could collect over thousands of points per second. It could generate the high accuracy model from the data and low the costs of the data processing at the same time because of the speed of measurements. In comparison to traditional methods where some weight on a rope was hanging from the top of the building, terrestrial laser scanning is an innovative technology where we could collect the whole spatial information about the object of interest with high accuracy. At last, it has to be remembered, that every of new construction has to be evaluate with the real estate markets, especially in urban areas in case of study, described in this article [7][8].

\section{References}

1. P. Tysiac, A. Wojtowicz, K. Bobkowska, INTCESS 2017, 743 (2017)

2. K. Bobkowska, M. Przyborski, P. Tysiąc, INTCESS 2017,813 (2017)

3. A. Janowski, K. Nagrodzka-Godycka, J. Szulwic, P. Ziolkowski, Computers and Concrete 18 (3), 405 (2016)

4. C. Suchocki, J. Katzer, Construction and building materials 122, 400 (2016)

5. F. Bosche, M. Ahmed, Y. Turkan, C.T. Haas, R. Haas, Automation in Construction 49, 201 (2015)

6. E. Urbańska-Galewska, K. Żółtowski, J. Ziółko, D. Kowalski, A. Perliński, T. Białek, K. Dobiszewski, M. Miśkiewicz, M. Nowicki, XXIV Konferencja Naukowo-Techniczna. Awarie Budowlane 2009. Zapobieganie, diagnostyka, naprawy, rekonstrukcje, 713 (2009) (in Polish)

7. M. Renigier-Biłozor, A. Biłozor A., R. Wiśniewski, Land Use Policy 61, 511 (2017)

8. M. Renigier-Biłozor, R. Wiśniewski, A. Biłozor, A. Kaklauskas, International Journal of Strategic Property Management 18 (2), 198 (2014) 